\title{
HAPPINESS, FREEDOM AND VALUES IN MODERN SOCIETY
}

In Happiness And Contemporary Society : Conference Proceedings Volume (Lviv, March, 20-21, 2021). Lviv: SPOLOM, 2021. P. 49-53. https://doi.org/10.31108/7.2021.8

ISBN 978-966-919-697-2 
https://doi.org/10.31108/7.2021.8

\section{BULJUBAŠIĆ Ema}

Philosophy - MA in Education and English Language and Literature - MA in Translation and Interpreting Studies

Ph.D. student, Department of Philosophy, Social and Human Sciences, and Education Università degli Studi di Perugia (Perugia, Italy)

\section{HAPPINESS, FREEDOM AND VALUES IN MODERN SOCIETY}

Pursuit of happiness is a highly valued human ambition that seems impossible to achieve in modern society. Ancient Greek philosophers, especially Aristotle's concept of eudaimonia, present a theoretical starting point for defining happiness and bringing it firmly into relation with values. Philosopher Herbert Marcuse provides a valuable analysis of modern industrialized society explaining man's loss of freedom in exchange for comfort and the self-perpetuating mechanism of consumerism that keeps people under willingly oppressed by imposing false needs. Consumerism also causes a distortion of people's values and alienates them from their true values causing them psychological damage. Using Dr. Melanie Joy's analysis of the psychological importance of living in accordance with one's values and the distortion of values as a manipulation tactic common to different systems of oppression (racism, sexism, speciesism) we will identify two prerequisite conditions for achieving happiness: freedom and the alignment of values and behavior.

Key words: happiness, freedom, values, false needs, consumerism

\section{Introduction}

The pursuit of happiness is among the most common human ambitions, one that is valued so highly that it is granted as a right in the United States Declaration of Independence. While the ambition to pursue happiness can be central to an individual's life, definitions of happiness can differ greatly from one individual to another and can change over time giving the impression that one may discover one's concept of happiness was mistaken. In order to try to better understand what is necessary for achieving happiness we will consider the concept of happiness originating from ancient Greek philosophy and try to analyze the conditions in modern society that influence our attempts at achieving happiness today. Taking the frequent occurrence of diagnoses such as depression as symptomatic of a significant lack of happiness in modern society we will explore some possible causes of such a state of affairs using Marcuse's philosophical analysis of modern industrialized society. Another key element of Marcuse's critical analysis is his view on the position values were assigned in modern industrial society which we will bring into contrast with Aristotle's view of the highest good one could achieve being a life lived according to one's values. Additionally, we will rely on Dr. Melanie Joy's evaluation of the importance of living according to one's values. Finally, in order to contribute to a better understanding of happiness instead of analyzing the multitude of specific life goals one may argue would contribute to one's happiness we will attempt to identify the necessary conditions for achieving happiness. 


\section{A brief outline of ancient and modern concepts of happiness}

In ancient Greek philosophy happiness was considered as a general state of wellbeing rather than a psychological or emotional state. Philosophers posed the question of the most desirable life, the best life one could live and suggested different answers in accordance with their philosophical views. The element they had in common was living a moral or virtuous life. It was generally believed that it is not possible to live a good life if one did not live in accordance with reason and morality. Even Epicurus, who advocated hedonism as the most desirable way of life, believed that living in accordance with values is necessary if one is to achieve pleasure, which may surprise those who have only heard the word hedonism used to describe a shallow and empty pursuit of simple pleasures. The concept of hedonism originating from Epicurus is not greedy or insatiable but instead views pleasure as the absence of pain which can best be achieved through rational control of one's desires.

Our concept of happiness has evolved in alignment with the changes in our society. In the modern world it is easy to confuse the fulfillment of one's desires with happiness, or rather, to equate having unmet desires with unhappiness. Judging by the number of diagnosed and self-reported instances of depression, our society is characterized by a marked lack of happiness. For some happiness remains elusive, something continuously attempted but never achieved, while some consider the pursuit itself to be futile, happiness a hallow dream utilized as a marketing scheme. According to philosopher Herbert Marcuse this is nothing more than a symptom of modern consumerism. Every day we are bombarded with different images showing us what happiness is supposed to look like and suggesting a growing list of material possessions necessary for the fulfillment of all our desires. Marketing messages are ubiquitous on all social platforms, media or news outlets to the point that it is virtually impossible to undertake any task without encountering some sort of commercial or promotional material. While the omnipresence of marketing messages is a necessary wheel in the machine of global capitalism that keeps the consumers diligently fulfilling their role, it is worth exploring the effect this rampant consumerism has had on our concept of happiness, particularly because the growing presence of marketing messages in our lives has become normalized in our society. This denotes the absence of resistance toward the state of things that Marcuse identifies as characteristic of the new system of control that is built into modern industrialized consumer society.

\section{Freedom and values in modern society according to Marcuse}

Marcuse describes life in modern industrialized society as "a comfortable, smooth, reasonable and democratic unfreedom". Man is no longer in physical danger, he does not need to fight for his life, technology gives him comfort in his everyday activities, therefore he is inclined to accept the loss of freedom and obligation to be a productive member of the work force as reasonable and justified. Society maintains for him an illusion of freedom, he is not a slave, he is simply given a choice between working and starving. Thus man willingly becomes a part of the industrial process driven by desires he perceives as his own. Marcuse describes society based on technology and consumerism as totalitarian in its economic and technological manipulation of man's needs. 
Global industrialization is driven by ever increasing consumption. It is a machine that perpetuates its own existence by continuously increasing consumer demand. The key to achieving this is subtle manipulation of people's needs and desires, one of the methods being the omnipresence of marketing messages that we have previously mentioned. Marcuse explains that this system of dominance manipulates people by imposing false needs and then using desires they are conditioned to perceive as their own to keep them complacent, diligently working and consuming. The basis of this theory is the differentiation of true and false needs: true being only vital needs, i.e. those necessary for survival (food, clothing, shelter), and false being needs that are imposed on us from above in such a way that we feel like they are truly necessary such as buying an excessive amount of material possessions or buying things we have no use for or buying newer models of things we already have just because it is available. False needs are repressive because they serve to keep people in their assigned role of worker and consumer and maintain the existing social order. The most important aspect of this manipulation that needs to be considered here is the fact that it denies people their freedom giving them an illusion of freedom and choice instead. If we have the choice to decide which products to buy but not the choice to stop buying, there is no real freedom available to us. Of course, the choice to opt out of consuming would be fatal to consumerism and industrialized society.

Another important consequence of the role of perpetual consumer being imposed upon people is the development of the belief that happiness can be bought and it is psychologically damaging. People are continuously being led to believe that acquiring material possessions will bring them joy and happiness, and also that their standard of living is increasing which becomes an additional argument in favor of the whole system. Marcuse argues that having longer work days in exchange for material gain is in fact not an increase in the standard of living but a reduction of freedom. Loss of freedom is not the only significant consequence of consumer driven industrialization, there is also the loss of natural environment, clean air and water and proximity of nature. I agree with Marcuse that a real increase in the standard of living would have to include clean air and water, free time and proximity of nature to spend it in. This distortion of values is part of the problem of consumerism. Good, beauty, peace and justice cannot be scientifically explained and therefore become unreasonable goals, mere ideals reduced to subjective individual choices and opinions, not worthy of opposing the reigning values of consumerism. We will explore this distortion of values as a possible cause of the apparent lack of achieved happiness in modern society.

\section{Aristotle's concept of eudaimonia}

When thinking about the most desirable life Aristotle chose eudaimonia as the goal of the ideal life. The term is commonly translated as happiness, even though his concept of eudaimonia differs somewhat from the modern concept of happiness. In Aristotle's view eudaimonia was the only thing worth achieving for its own sake while wealth, courage or glory were only worth in relation to other things. Eudaimonia is achieved by living a virtuous life which means taking action based on our values and thus actively living virtuously. Since reason differentiates man from animals, Aristotle believes that physical pleasure, which is the goal of animals, cannot be man's goal. Man should use reason to determine the best course of action in accordance with the highest values and 
develop his own virtuous nature by consistently acting according to his values. In Aristotle's philosophy we see the link between happiness and values.

\section{Identifying the necessary conditions for achieving happiness}

Instead of trying to determine the exact form happiness should take, whether ways of working and living or thoughts or practices that might bring happiness, we will attempt to find the prerequisite conditions for happiness. Based on our research so far we will identify the conditions that are necessary for achieving happiness. For the pursuit of happiness to be possible one must first have freedom. This is implied in the U.S. Constitution ("life, liberty and pursuit of happiness") as well as in Aristotle's concept of eudaimonia. As seen from Marcuse's analysis of modern industrial society man has lost his freedom when he became an obedient consumer, essentially exchanging freedom for comfort. This might be the cause of the apparent difficulty modern people are experiencing in achieving happiness.

The second prerequisite condition for achieving happiness is living in accordance with one's values.

Melanie Joy, a Harvard-educated psychologist, explains that dominant systems or social powerarchies such as racism, sexism, classism and speciesism, employ strategies of manipulation by which they convince people that those systems of oppression are normal, natural and necessary, and therefore justified, which is not in accordance with people's true values. Similarly, Marcuse identified the imposition of false needs as the manipulation tactic used to keep people willfully oppressed by leading them to accept consumerism as normal, natural and necessary. Joy further explains that most people need to feel that they are living a moral life. Acting against our values causes us to feel a moral discomfort, a conscious or unconscious feeling of guilt, which can cause a form of cognitive dissonance. Compassion, justice and honesty are thought to be universal values and we often disregard them in favor of maintaining dominant narratives and satisfying false needs. It is understandable that this causes us deep psychological discomfort even if we cannot identify its source and this could easily lead to feelings of anxiety, unhappiness or even depression. We can now define the prerequisite conditions for happiness as the alignment of values and behavior and, of course, freedom.

\section{Conclusion}

Pursuit of happiness is among the most common and valued human ambitions, yet it often seems that happiness is impossible to achieve in modern society. There are some key characteristics of modern society we can identify as contributing causes to the common failure to obtain happiness, development of psychological discomfort and subsequently often even depression. Marcuse's analysis of modern industrialized society provides us with an account of the destructive mechanics of consumerism that needs to impose false needs unto people as a means of self-perpetuation and consequently causes a distortion of values. As seen from early philosophical thought on the subject of happiness the achievement of happiness has nothing to do with obtaining material wealth or physical pleasure, instead it is firmly tied to living a virtuous life, in other words living in accordance with one's values. Dr. Joy's work provides a psychologist's perspective and confirms the vital interconnectedness of happiness and values. She identifies compassion, justice and honesty as universal values and explains how 
dominant systems or social powerarchies such as racism, sexism, classism and speciesism utilize strategies of manipulation whereby they convince people that those systems of oppression are normal, natural, and necessary and therefore justified, which is not in accordance with people's true values. Acting against our true beliefs causes us psychological discomfort that prevents us from achieving happiness and may even be diagnosed as depression. In conclusion, this research has determined that freedom and the alignment of values and behavior are prerequisite conditions for happiness.

\section{REFERENCES}

1. Aristotle and Happiness. Source: https://www.pursuit-of-happiness.org/history-ofhappiness/aristotle/

2. Craig, Heather. Philosophy of Happiness in Life (+ Aristotle's View). Published in October, 2020. Source: https://positivepsychology.com/philosophy-of-happiness/

3. Joy, Melanie. Beyond Beliefs. New York, 2018.

4. Joy, Melanie. Powerarchy. Oakland, CA, 2019.

5. Marcuse, Herbert. Čovjek jedne dimenzije. Sarajevo, 1968. Original title: One dimensional man.

6. Philosophy of Happiness. Source: https://slife.org/philosophy-of-happiness/ 